\section{D Bio-Printing: An INTRODUCTION TO A NeW APPROACH For CANCER PATIENTS AT THE INTERFACE OF ART AND MEDICINE}

Eugen Bogdan Petcu (academic pathologist), Griffith University School of Medicine Gold Coast Campus, QLD 4222, Queensland Eye Institute, Brisbane, QLD 4001, Australia. Email: <e.petcu@griffith.edu.au>.

See $<$ www.mitpressjournals.org/toc/leon/50/2 $>$ for supplemental files associated with this issue.

\section{Submitted: 26 March 2016}

\section{Abstract}

Cancer patients require a complex multidisciplinary therapy. In this context the 3D additive biological manufacturing could represent a significant development with potential significant medical and social consequences. This article reviews the $3 \mathrm{D}$ bioprinting methods and clinical settings in which this new revolutionary method could be applied. Apart from the actual field of post-cancer therapy prosthetics and medical education, this method could be applied in the actual molecular cancer research and organ regeneration/fabrication. Considering all of these, it is possible that in the future, 3D biological printing could be used on a regular basis in clinical oncology.

Oncological therapy is complex and includes molecular and tissue diagnosis and targeted chemo- and immunotherapy and surgical resection. Currently, cancer is diagnosed at an early stage and an increasing number of these patients are long-term survivors. For those who had surgery, surviving without a certain organ or a part of their body could be associated with a functional deficit of a system and a significant negative psychological impact. In this context, the new methodology of 3D additive manufacturing and printing with its biological variant may have potentially multiple effects, providing not only a biologically "friendly" prosthesis but also a biological scaffold-based man-made alternative that could subsequently replace the organs surgically removed. We would like to highlight not only the biomedical aspect of these methods but also the artistic implications, as the bio-compatible prosthesis and scaffolds must provide restitution ad integrum of functionality, while in parallel they should be esthetically acceptable by the patient and society. The principle that art derives its topics from the study of the human body and nature applies also in this context, albeit from a classical realistic perspective. The newly created 3D printed (3DP) biological prosthetic devices must replicate life as much as possible. Preferably, the newly created biological structures should be indistinguishable from the actual natural organ.

Currently, several 3DP methods are available; these are summarized in Table 1. Interestingly, the newest method, the so-called integrated tissue-organ printer, allows biofabrication in parallel of several types of tissues: bone, muscle and cartilage [6]. This technique seems to have a considerable impact, as segments of bones or entire limbs are often amputated due to cancer and other pathological conditions.

Fabrication of 3DP of scaffolds for bone regeneration could also be extrapolated with ease to other organs, such as internal organs. Recent studies have reported that polycaprolactone (PCL) used with a bio-ink based on hepatocytes, human umbilical vein endothelial cells and human lung fibroblasts promote formation of liver tissue [9]. All these data are encouraging, but a significant problem is represented by the actual modulation of the local vascular network, which is required to nourish the tissues. Production of pre-vascularized 3DP scaffolds might represent an

Table 1. 3D Printing Methods

\begin{tabular}{|c|c|c|c|}
\hline 3DP Method & Materials and Products & Comments & References \\
\hline $\begin{array}{l}\text { Stereo lithography } \\
\text { appearance (SLA) }\end{array}$ & $\begin{array}{l}\text { SLA produces biological 3D scaffolds as a } \\
\text { result of a cross-linking action of a UV laser } \\
\text { upon a liquid biological material. The resolu- } \\
\text { tion of the printed material is around } 0.1 \mathrm{~mm} \text {. }\end{array}$ & $\begin{array}{l}\text { The modern SLA protocols use poly- } \\
\text { propylene and diethyl fumarate as well } \\
\text { as bis-acylphosphine oxide and are } \\
\text { employed in creating "bony" scaffolds. }\end{array}$ & Cooke et al. (2003) [1] \\
\hline $\begin{array}{l}\text { Fused deposition } \\
\text { modelling (FDM) }\end{array}$ & $\begin{array}{l}\text { FDM requires an input from a computer-aided } \\
\text { design (CAD) system. This technology pro- } \\
\text { duces } 3 \text { DP biological products with a high } \\
\text { degree of accuracy [2]. } \\
\text { Recent reports reveal that bone scaffolds } \\
\text { can be manufactured with a high degree of } \\
\text { precision with this method utilizing poly- } \\
\text { lactic acid, which allows the manufacture } \\
\text { of a biologically compatible product with a } \\
\text { superior elastic quality [3]. }\end{array}$ & $\begin{array}{l}\text { FDM biofabricates scaffolds that have a } \\
\text { well-developed pore network. Moreover, } \\
\text { the pore's shape and size can be adjusted } \\
\text { and poly-caprolactone scaffolds allowed } \\
\text { seeding with mesenchymal stromal } \\
\text { cells [4]. }\end{array}$ & $\begin{array}{l}\text { Chen et al. (2016) [2] } \\
\text { Naghieh et al. (2016) [3] } \\
\text { Ostrowska et al. (2016) [4] }\end{array}$ \\
\hline $\begin{array}{l}\text { Selective laser } \\
\text { sintering (SLS) }\end{array}$ & $\begin{array}{l}\text { SLS requires the use of pure poly-caprolac- } \\
\text { tone (PCL) spheres and hydroxyapatite (HA). } \\
\text { One of the most important characteristics } \\
\text { of bone microstructure and physiology - } \\
\text { the porosity that allows various functional } \\
\text { exchanges between bone and surrounding } \\
\text { tissues - can be achieved by SLS [5]. }\end{array}$ & $\begin{array}{l}\text { This technique makes possible fabrication } \\
\text { of } 3 D \text { bone scaffolds with very high } \\
\text { mechanical resilience, and both in vivo } \\
\text { and in vitro experiments have indicated } \\
\text { that SLS-scaffolds promote proliferation } \\
\text { of supporting cells as well as adhesion } \\
\text { and vascular network development in } \\
\text { the newly created structure [5]. }\end{array}$ & Du et al. (2015) [5] \\
\hline $\begin{array}{l}\text { Integrated tissue- } \\
\text { organ printer } \\
\text { (ITOP) }\end{array}$ & $\begin{array}{l}\text { ITOP is used for 3DP of bone in parallel with } \\
\text { biofabrication of cartilage and muscle [6]. } \\
\text { Loading of osteogenic scaffolds with mesen- } \\
\text { chymal cells suspended in Pluronic F-127 } \\
\text { hydrogel promotes optimal cell proliferation } \\
\text { and osteogenesis [7]. }\end{array}$ & $\begin{array}{l}\text { If the } 3 \text { DP polycaprolactone scaffolds } \\
\text { are combined with recombinant human } \\
\text { bone morphogenic protein-2 (rhBMP2) } \\
\text { attached via polydopamine (DOPA), the } \\
\text { cell proliferation and osteoconductivity } \\
\text { are very efficient [8]. }\end{array}$ & $\begin{array}{l}\text { Kang et al. (2016) [6] } \\
\text { Liu et al. (2016) [7] } \\
\text { Lee et al. (2016) [8] }\end{array}$ \\
\hline
\end{tabular}


attractive option [10], but it is known that cancer growth depends on a good vascular supply. Therefore, any new 3DP that contains pro-angiogenic factors or growth factors would be contraindicated in cancer patients at least until they are declared with the highest degree of confidence "free of tumor." Based on the data taken from a patient with lung cancer, Mayer et al. (2015) have been able to create by $3 \mathrm{D}$ additive nonbiological manufacturing an anthropomorphic thorax phantom that, remarkably, was associated with a moving surrogate tumor. This product was used successfully in calculating the best radiation dosimetry required by the patient [11]. Based on CT data an anthropomorphic breast cancer phantom has been developed. The authors used urethane-based polymers, beeswax and oil.

Eggshells were introduced in the construct and given the role of microcalcification. This construct was used in the context of anatomical evaluation, and it might represent a significant tool in quality control studies and virtual clinical trials [12]. In addition, 3D bio-printing will enable the scientists to recreate in vitro the actual cancer diagnosed initially in patients. Song et al. (2014) advocate the use of hydrogels to $3 \mathrm{D}$ print the actual microenvironment of tumors in order to evaluate the pro-angiogenic metastatic ability of malignant cells [13]. This represents a major development for those interested in evaluating the aggressiveness of various types of malignant lesions as they will be able to real-time intervene in the actual tumor environment. Interestingly, Zhao et al. (2014) have managed to 3D print Hela cancer cells in parallel with extracellular-like components such as fibrinogen, alginate and gelatin hydrogels, creating tridimensional cervical tumors in vitro. This represents a significant method that will enable a better understanding of this type of cancer $[14,15]$. The 3D printing of various cancer cells will enable us to characterize tumor behavior and the response of its surrounding environment. Also a "tumor-on-a chip" could be created. Potentially, this could make possible a complete understanding of cancer biology. Recently published reports indicate that cancer 3DP based on radiological data from patients improves surgical outcomes. Son et al. (2015) report a case of primary cardiac schwannoma that was successfully removed after prior 3DP of the heart based on a chestcomputed tomography evaluation [16]. Also, 3DP seems to be very useful in hepatic tumor resections, as the surgeon could practice the actual procedure on tridimensional printouts $[17,18]$. Additive 3DP has been used successfully for surgical training and practice before thoracic surgery. In this setting, models of 3DP pulmonary arteries can be utilized to improve surgical skills and planning as well as anatomical skills of the surgeon [19]. Either way, the potential artistic and psychological consequences of 3D clinical printing are significant.

The moral and ethical aspects of this new therapeutic method at the interface of art and clinical medicine are not yet fully established. The aesthetic evaluation of "perfection" associated with the 3DP of any body part is highly debatable; it depends on the patient's choice. While it is possible to acquire a "perfect body" even after cancer surgery this would certainly create an array of ethical questions for both Western and Oriental societies. The 3DP could represent a lifesaving procedure for a wide range of patients, but it may prove to be futile in some cases. At the present time, we are far from printing perfectly functional organs or body parts that could be "transplanted" to cancer patient in a reasonable period of time. We cannot ignore the possibility that one day 3DP could be a clinical procedure widely adopted, but currently it is a method that is mostly used in research. As with any other cancer therapy, it is very debatable if by 3DP we will add years to life or life to years. However, at least theoretically, in the perpetual quest for the "beauty" of mankind, a perfectly clinical functional 3DP method could create the same issues as plastic-aesthetic surgery, with similar social implications.

\section{References and Notes}

1. M.N. Cooke, et al., "Use of Stereolithography to Manufacture CriticalSized 3D Biodegradable Scaffolds for Bone Ingrowth," Journal of Biomedical Materials Research Part B: Applied Biomaterials 64, No. 2, 65-69 (15 February 2003).

2. H. Chen et al., "Application of FDM Three-Dimensional Printing Technology in the Digital Manufacture of Custom Edentulous Mandible Trays," Scientific Reports 6 (14 January 2016) 19207. doi: 10.1038/srep19207.

3. S. Naghieh et al., "Numerical Investigation of the Mechanical Properties of the Additive Manufactured Bone Scaffolds Fabricated by FDM: The Effect of Layer Penetration and Post-Heating," Journal of the Mechanical Behavior of Biomedical Materials 59 (2016) 21-250.

4. B. Ostrowska et al., "Influence of Internal Pore Architecture on Biological and Mechanical Properties of 3D Fibre Deposited Scaffolds for Bone Regeneration," Journal of Biomedical Materials Research Part A (8 January 2016) doi:10.1002/jbm.a.35637.

5. Y. Du et al., "Microsphere-Based Selective Laser Sintering for Building Macroporous Bone Scaffolds with Controlled Microstructure and Excellent Biocompatibility," Colloids and Surfaces B: Biointerfaces 135 (1 November 2015) pp. 81-89.

6. HW Kang et al., "A 3D Bioprinting System to Produce Human-Scale Tissue Constructs with Structural Integrity," Nature Biotechnology (15 February 2016). doi: 10.1038/nbt.3413 [Epub ahead of print].

7. A. Liu et al., "3D Printing Surgical Implants at the Clinic: A Experimental Study on Anterior Cruciate Ligament Reconstruction," Scientific Reports 6 (15 February 2016) 21704.

8. S.J. Lee et al., "Surface Modification of 3D-Printed Porous Scaffolds Via Mussel-Inspired Polydopamine and Effective Immobilization of Rhbmp-2 to Promote Osteogenic Differentiation for Bone Tissue Engineering," Acta Biomaterialia 16 (8 February 2016) pii:S1742-7061, 30050-2.

9. Lee et al., "Development of a 3D Cell Printed Construct Considering Angiogenesis for Liver Tissue Engineering," Biofabrication (12 January 2016) 8 (1):015007. doi:10.1088/1758-5090/8/1/015007.

10. G.D. Barabaschi et al., "Engineering Pre-vascularized Scaffolds for Bone Regeneration," Advances in Experimental Medicine and Biology $\mathbf{8 8 1}$ (2015) pp. 79-94.

11. R. Mayer et al., "3D printer Generated Thorax Phantom with Mobile Tumor for Radiation Dosimetry," Review of Scientific Instruments (July 2015) 86(7):074301. doi: 10.1063/1.4923294.

12. N. Kiarashi et al., "Development of Realistic Physical Breast Phantoms Matched to Virtual Breast Phantoms Based on Human Subject Data," Medical Physics (July 2015) 42(7):4116-4126.

13. H.H. Song, K.M. Park and S. Gerecht, "Hydrogels to Model 3D in Vitro Microenvironment of Tumor Vascularization," Advanced Drug Delivery Reviews (15 December 2014) 79-80:19-29.

14. Y. Zhao et al., "Three-Dimensional Printing of Hela Cells for Cervical Tumor Model in Vitro" Biofabrication 3 (6 September 2014):035001. doi: 10.1088/1758-5082/6/3/035001.

15. T.Q. Huang et al., "3D Printing of Biomimetic Microstructures for Cancer Cell Migration," Biomedical Microdevices 16, No. 1, 127-32 (2014).

16. K.H. Son et al., "Surgical Planning by 3D Printing for Primary Cardiac Schwannoma Resection," Yonsei Medical Journal (November 2015) 56, No. 6, 1735-1737.

17. K. Takagi et al., "Three-Dimensional Printing Model of Liver for Operative Simulation in Perihilar Cholangiocarcinoma," Hepatogastroenterology 61(136) (Nov-Dec 2014) 2315-2316.

18. C. Fang et al., "Application of 3D Visualization, 3D Printing and 3D Laparoscopy in the Diagnosis and Surgical Treatment of Hepatic Tumors," Nan Fang Yi Ke Da Xue Bao 35, No. 5, 639-645 (2015).

19. S.N. Kurenov et al., "Three-Dimensional Printing to Facilitate Anatomic Study, Device Development, Simulation, and Planning in Thoracic Surgery," The Journal of Thoracic and Cardiovascular Surgery 4 (April 2015) 149:973-979. 